\title{
Carbapenems Resistance Klebsiella Species Isolated from Various Clinical Samples in a Tertiary Care Hospital
}

\author{
Rajeswari Jayakumar*, Vijayalakshmi Arumugam and Meerah Srinivasagam
}

Department of Microbiology, Chengalpattu Medical College, Chengalpattu, Kancheepuram

District, Tamilnadu, India

*Corresponding author

\begin{tabular}{|c|c|}
\hline & A B S T R A C T \\
\hline & $\begin{array}{l}\text { Carbapenems are one of the } \beta \text {-Lactam antibiotics with a broad spectrum of antibacterial } \\
\text { activity. Inappropriate use of this antibiotic can produce resistance strains by production of } \\
\text { carbapenemases enzyme. The Klebsiella pneumoniae carbapenemase (KPC) is the most }\end{array}$ \\
\hline Keywords & $\begin{array}{l}\text { important mechanism of enzymatic resistance seen in Enterobacteriaceae isolated } \\
\text { especially Klebsiella pneumoniae. The aim and objectives of this study was isolation and }\end{array}$ \\
\hline $\begin{array}{l}\text { Klebsiella } \\
\text { pneumoniae, }\end{array}$ & $\begin{array}{l}\text { detection of the Carbapenem resistant Klebsiella species strains with phenotypic methods. } \\
\text { Out of } 11248 \text { samples, } 602 \text { Klebsiella species }(33.7 \%) \text {, were isolated by standard }\end{array}$ \\
\hline $\begin{array}{l}\text { Carbapenem } \\
\text { Resistance. }\end{array}$ & Microbiological protocol \& Antibiotic susceptibility test was performed by disk diffusion \\
\hline Resistance. & method with CLSI guidelines. A total 602 Klebsiella species strains were isolated. Of the \\
\hline Article Info & $\begin{array}{l}602 \text { isolates of Klebsiella species, Klebsiella pneumoniae were } 323(54 \%) \text { and Klebsiella } \\
\text { oxytoca were } 279(46 \%) \text {. Antibiotic sensitivity pattern revealed maximum resistant to }\end{array}$ \\
\hline $\begin{array}{l}\text { Accepted: } \\
\text { 23 June } 2017 \\
\text { Available Online: } \\
10 \text { July } 2017\end{array}$ & $\begin{array}{l}\text { Cephalosporins (22\%) followed by Ciproflaxacin }(14 \%) \text {, Gentamycin (10\%), Ceftriaxone - } \\
\text { Clavulanate (8\%), Piperacillin- Taxobactum (7\%), Amikacin (7\%). Out of } 602 \text { Klebsiella } \\
\text { spp, Carbapenems resistant isolates were } 28(5 \%) \text {. All the } 28(100 \%) \text { isolates were resistant } \\
\text { to Meropenem and } 23(83 \%) \text { isolates were resistant to Imipenem. Carbapenems are the }\end{array}$ \\
\hline & $\begin{array}{l}\text { drug of choice for multidrug resistant infections, like ESBL and AmpC producing isolates, } \\
\text { but resistance to carbapenems by the production of carbapenamases and various other } \\
\text { mechanisms has limited therapeutic options to use carbapenem drugs. }\end{array}$ \\
\hline
\end{tabular}

\section{Introduction}

Carbapenems are a most important antibacterial drugs used for the treatment of Extended spectrum Beta Lactamases and AmpC lactamases producing organisms mainly Enterobacteriaceae family. Improper and inappropriate use of this drug induces Carbapenem resistance by an enzyme, Klebsiella pneumoniae carbapenemase (KPC).

Klebsiella pneumoniae carbapenemase (KPC) is a enzyme produced by Enterobacteriaceae family mainly Klebsiella species that offer resistance to carbapenems and other Beta lactam antibiotics by direct hydrolyzing activity on this drugs, reduced in bacterial outer membrane permeability and increased production of ESBL, AmpC lactamases and carbapenemase (KPC) (Masoume, 2015; Nordmann et al., 2012)

Klebsiella pneumoniae carbapenemase (KPC) was, first described in 1996 in North Carolina, USA (Yigit et al., 2001) 
The main purpose of this study was to detect the carbapenem resistant Klebsiella species among various clinical samples. Because the emergence of Klebsiella pneumoniae carbapenemase (KPC) producing bacteria has become a significant global health challenge.

\section{Materials and Methods}

The study was a retrospective study conducted over a period of one year in a tertiary care hospital. Klebsiella species isolates from various clinical samples like Urine, pus, Blood, sputum and throat swab received during the study period (April 2016 to March 2017) were included in the study.

Out of 11248 clinical samples received and processed, identification of Klebsiella species was done by morphology of the colonies on the MacConkey plate and blood agar plate, Catalase test, Oxidase test, Hanging drops method, Nitrate reduction test, IMViC test and sugar fermentation test.

The Antibiogram test done by Kirby Bauer disc diffusion method was carried on Cationic adjusted Mueller Hinton agar with the following antibiotic disc as per CLSI

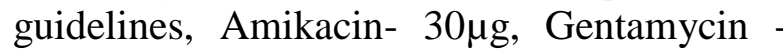
$10 \mu \mathrm{g}$, Ciproflaxacin $-5 \mu \mathrm{g}$, Ceftriaxone $-30 \mu \mathrm{g}$, Cefotaxime $-30 \mu \mathrm{g}$, Ceftriaxone / Clavulanate $-30 \mu \mathrm{g} / 10 \mu \mathrm{g}, \quad$ Piperacillin/ Taxobactum $30 \mu \mathrm{g} / 10 \mu \mathrm{g}$, Imipenem $-10 \mu \mathrm{g}$ and Meropenem $-10 \mu \mathrm{g}$.

\section{Results and Discussion}

Out of 11248 samples, 602 Klebsiella species were isolated from various clinical samples. Of the 602 isolates Klebsiella pneumoniae were $323(54 \%)$ and Klebsiella oxytoca were 279 (46\%) (Table 1).

The more number of pathogen isolated from urine $300(50 \%)$. Organisms isolated from pus, sputum, blood and swab were 165
(27.4\%), $68(11.2 \%), 42(7 \%)$ and $27(4.4 \%)$ respectively.

Antibiotic sensitivity pattern revealed maximum resistant to Cephalosporins (22\%) followed by Ciproflaxacin (14\%), Gentamycin (10\%), Ceftriaxone -Clavulanate (8\%), Piperacillin- Taxobactum (7\%), Amikacin (7\%).

Out of 602 Klebsiella spp, Carbapenems resistant isolates were $28(5 \%)$. All the 28 $(100 \%)$ isolates were resistant to Meropenem and $23(83 \%)$ isolates were resistant to Imipenem.

In this study, 28 Carbapenems resistance isolates, 23 were male patients, 5 were female patients.

Carbapenems resistant strain was isolated from pus $12(43 \%)$ followed by urine $9(32 \%)$, sputum $5(18 \%)$ and blood 2(7\%).

Of 28 Carbapenems resistant strains, 16 (57\%) were belongs to Klebsiella oxytoca and $12(43 \%)$ were belongs to Klebsiella pneumoniae. All the strains were isolated from hospitalized patients.

Klebsiella pneumoniae carbapenemase (KPC) is a enzyme produced by Enterobacteriaceae family mainly Klebsiella species that offer resistance to carbapenems and other Beta lactam antibiotics. This is by direct hydrolyzing activity on the drugs, reduction in bacterial outer membrane permeability for the drugs and increased production of ESBL, AmpC lactamases and carbapenemase (KPC).

Acquisition of Carbapenem resistant Klebsiella spp may be due to reduced permeability of drugs (Nordmann et al., 2012). Falagas et al., (2007) have reported as previous use of antipseudomonal penicillins, quinolones and Carbapenems are the 
important risk factors for development of Carbapenem resistant strains. Prolonged hospitalization, intensive care unit stay, improper infection control measures and use of $\mathrm{H} 2$ receptor antagonist reduces gastric acidity and leads to colonization of Carbapenem resistant Klebsiella spp (Table 2). Out of 11248 samples, 602 Klebsiella species were isolated from various clinical samples. Of the 602 isolates Klebsiella pneumoniae were 323 (54\%) and Klebsiella oxytoca were 279 (46\%). The more number of pathogen isolated from Urine 300 (50\%). Organisms isolated from Pus, Sputum, Blood and Swab were 165 (27.4\%), 68 (11.2\%), 42 (7\%) and $27(4.4 \%)$ respectively.

Table.1 Klebsiella species isolated from various clinical samples

\begin{tabular}{|c|c|c|c|c|}
\hline \multirow{2}{*}{ Samples } & \multicolumn{3}{|c|}{ Organisms } & \multicolumn{2}{c|}{ Total } \\
\cline { 2 - 5 } & $\begin{array}{c}\text { Klebsiella } \\
\text { pneumoniae }\end{array}$ & Klebsiella oxytoca & No & $\%$ \\
\hline Urine & 162 & 138 & 300 & 50 \\
\hline blood & 23 & 19 & 42 & 7 \\
\hline sputum & 36 & 32 & 68 & 11.2 \\
\hline pus & 91 & 74 & 165 & 27.4 \\
\hline swab & 11 & 16 & 27 & 4.4 \\
\hline Total & 323 & 279 & 602 & 100 \\
\hline
\end{tabular}

Table.2 Antibiotic sensitivity and resistant pattern of Klebsiella species isolated from various clinical isolates

\begin{tabular}{|c|c|c|c|c|}
\hline \multirow[b]{2}{*}{ Antibiotics } & \multicolumn{2}{|c|}{ Sensitive pattern } & \multicolumn{2}{|c|}{ Resistant pattern } \\
\hline & $\begin{array}{l}\text { Number of } \\
\text { isolates }\end{array}$ & $\begin{array}{c}\text { Percentage } \\
\%\end{array}$ & $\begin{array}{l}\text { Number of } \\
\text { isolates }\end{array}$ & $\begin{array}{c}\text { Percentage } \\
\%\end{array}$ \\
\hline Amikacin- 30 $\mu \mathrm{g}$ & 562 & 93 & 40 & 7 \\
\hline Gentamycin -10 $\mu \mathrm{g}$ & 541 & 90 & 61 & 10 \\
\hline Ciproflaxacin $-5 \mu \mathrm{g}$ & 519 & 86 & 83 & 14 \\
\hline Ceftriaxone $-30 \mu \mathrm{g}$ & 470 & 78 & 132 & 22 \\
\hline Cefotaxime $-30 \mu \mathrm{g}$ & 472 & 78 & 130 & 22 \\
\hline $\begin{array}{c}\text { Ceftriaxone / Clavulanate - } \\
\text { 30 } \mu \mathrm{g} / 10 \mu \mathrm{g}\end{array}$ & 555 & 92 & 47 & 8 \\
\hline $\begin{array}{c}\text { Piperacillin/ Taxobactum - } \\
\text { 30 } \mu \mathrm{g} / 10 \mu \mathrm{g}\end{array}$ & 562 & 93 & 40 & 7 \\
\hline Imipenem -10 $\mu \mathrm{g}$ & 574 & 95 & 28 & 5 \\
\hline 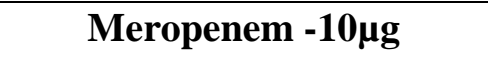 & 579 & 96 & 23 & 4 \\
\hline
\end{tabular}


Fig.1 Cabapenem resistant strains

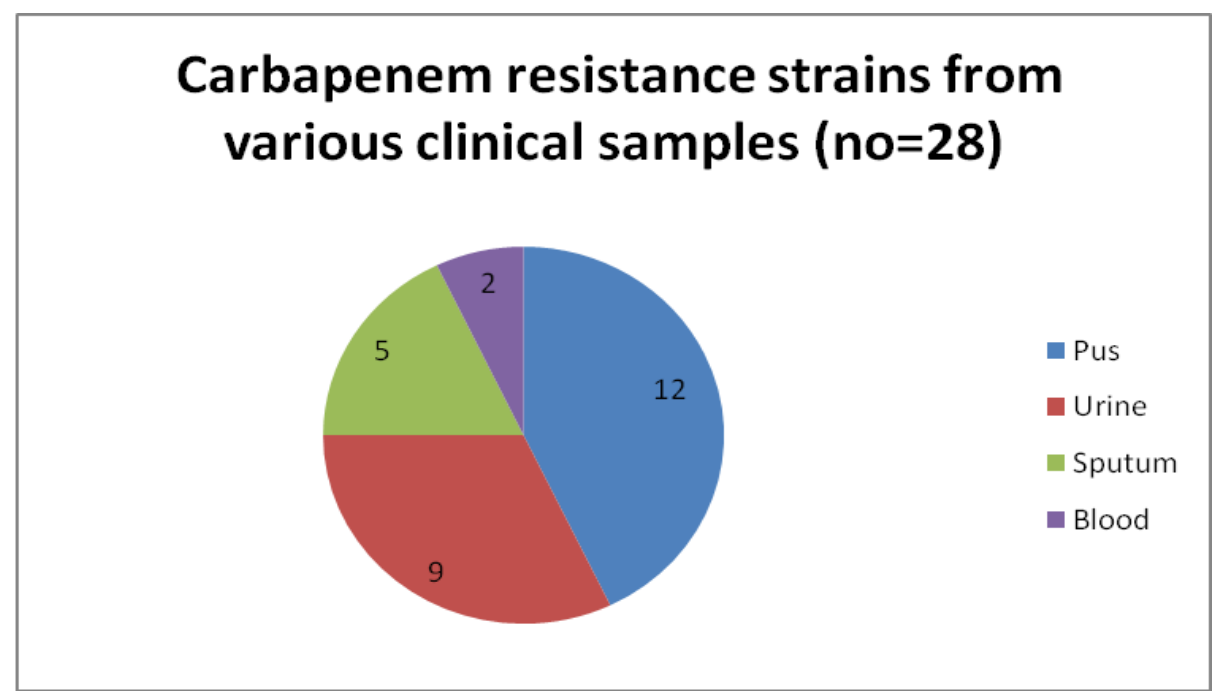

All the carbapenem resistance strains were isolated from Inpatient (100\%). This is due to prolonged antibiotic therapy, Intensive care unit stay, Multiple Invasive devices and Immunosuppressive drugs (Chia et al., 2010; Yigit et al., 2001).

In this study, among 28 Carbapenems resistant, Klebsiella spp $25(89 \%)$ isolated from male patients, $3(11 \%)$ isolated from female patients. This is agreement with the study conducted by Alves et al, in which they have reported as male (72.3\%) predominantly affected by KPC (Alves et al., 2013) (Fig. 1).

Among 28 Carbapenem resistant strains, 12 (43\%) isolated from Pus followed by Urine 9 (32\%), Sputum $5(18 \%)$ and Blood $2(7 \%)$, this is similar to study conducted by Gabriela Seibert et al., (2014) in which most of the Carbapenem resistant strains was isolated from surgical ward. Infections produced by Carbapenem resistant Klebsiella spp mainly in immunosuppressed patients who are hospitalized and/or who use invasive devices, such as catheters and tubes.

Of 28 Carbapenems resistant strains, 16 (57 $\%$ ) belongs to Klebsiella oxytoca and 13 (43
$\%)$ belongs to Klebsiella pneumoniae. This is not correlated with other studies because they found out that the Klebsiella pneumoniae mainly induces Carbapenemase enzymes that will degrade Carbapenem drugs and produces resistance.

Out of 28 Carbapenem resistant Klebsiella spp, 28 (100\%) isolates were resistant to Meropenem, $23(82 \%)$ isolates were resistant to Imipenem and the remaining $5(18 \%)$ were sensitive to Imipenem. A similar study conducted by Bratu et al., (2005) has reported as $80 \%$ resistant to Imipenem, $83 \%$ resistant to Meropenem. The different sensitivity pattern between imipenem and meropenem is due to different pharmacodynamic property among the carbapenem drugs (Joseph et al., 2004).

Antibiotic sensitivity pattern revealed maximum resistant to Cephalosporins (22\%) followed by Ciproflaxacin (14\%), Gentamycin (10\%), Ceftriaxone -Clavulanate (8\%), Piperacillin- Taxobactum (7\%), Amikacin (7\%). This multidrug resistance of Carbapenem resistant Klebsiella spp is due to carbapenems share a common structure with cephalosporins and penicillin. Carbapenem 
resistant organism can confer resistance to multiple various antimicrobial classes, like $\beta$ lactams, fluoroquinolones and aminoglycosides (Endimiani et al., 2009). Bratu et al., (2005) and Gasink et al., (2009) reported as KPC infections are always associated with high therapeutic failure and mortality rates.

Our study showed that $86 \%$ sensitive to amikacin and $61 \%$ sensitive to gentamicin. In a study conducted by Alves et al., (2013) reported as $97.5 \%$ sensitive to amikacin and $70 \%$ sensitive to gentamicin. The aminoglycoside is a good alternative drug for carbapenem resistant organisms.

In conclusion, carbapenems are the drug of choice for multidrug resistant infections, like ESBL and AmpC producing isolates, but resistance to carbapenems by the production of carbapenemase and various other mechanisms has limited therapeutic options to use carbapenem drugs. To combat the drug resistance we have to adhere strict infection control measures, and antibiotic policy.

\section{References}

Alves, A.P., Behar, P.R. 2013. Infecções hospitalares por enterobactérias produtoras de KPC em um hospital terciário do sul do Brasil. Rev AMRIGS, 57(3): 213-8.

Bratu, S., Mooty, M., Nichani, S., Landman, D., Gullans, C., Pettinato, B., et al. Emergence of KPC-possessing 2005. Klebsiella pneumoniae in Brooklyn, New York: epidemiology and recommendations for detection. Antimicrob. Agents Chemother., 49(7): 3018-20.

Castanheira, M., Sader, H.S., Deshpande, L.M., Fritsche, T.R., Jones, R.N. 2008. Antimicrobial activities of tigecycline and other broad-spectrum antimicrobials tested against serine carbapenemase- and metallobetalactamase producing entero bacteriaceae: Report from the SENTRY antimicrobial surveillance program. Antimicrob. Agents Chemother., 52(2): 570-573.

Centers for Disease Control and Prevention (CDC). Guidance for control of infections with carbapenem- resistant or carbapenemase-producing Entero bacteriaceae in acute care facilities. MMWR Morb. Mortal Wkly. Rep., 58(10): 256-60.

Chia, J.H., Su, L.H., Lee, M.H., et al. 2010. Development of high-level carbapenem resistance in Klebsiella pneumoniae among patients with prolonged hospitalization and carbapenem exposure. Microb. Drug Resist., 16(4): 317-325.

Endimiani, A., Hujer, A.M., Perez, F., Bethel, C.R., Hujer, K.M., Kroeger, J., Oethinger, M., Paterson, D., Adams, M., Jacobs, M., Diekema, D., Hall, G., Jenkins, S., Rice, L., Tenover, F, Bonomo, R. 2009. Characterization of blaKPC-containing Klebsiella pneumoniae isolates detected in different institutions in the eastern USA. J. Antimicrob. Chemother., 63(3): 427437.

Falagas, M.E., Rafailidis, P.I., Kofteridis, D., Virtzili, S., Chelvatzoglou, F.C., Papaioannou, V., et al. 2007. Risk factors of carbapenem resistant Klebsiella pneumoniae infections: a matched case-control study. $J$. Antimicrob. Chemother., 60(5): 112430.

Gabriela Seibert, et al. 2014. Nosocomial infections by Klebsiella pneumoniae carbapenemase producing enterobacteria in a teaching hospital. 12(3): 282-6.

Gasink, L.B., Edelstein, P.H., Lautenbach, E., 
Fishman, N.O. 2009. Risk factors and clinical impact of Klebsiella pneumoniae carbapenemase-producing K. pneumoniae. Infect. Control Hosp. Epidemiol., 30(12): 1180-1185.

Joseph, L., Kuti, et al. 2004. Pharmacodynamics of Meropenem \& Imipenem against Enterobacteriaceae, A. baumannii \& $P$. aeruginosa. Pharmacother., 24.

Masoume Bina, et al. 2015. Detection of the Klebsiella pneumoniae carbapenemase (KPC) in K. pneumoniae Isolated from the Clinical Samples by the Phenotypic and Genotypic Methods. Iranian $J$. Pathol., 10(3): 199- 205.

Nordmann, P., Poirel, L., Dortet, L. 2012. Rapid Detection of Carbapenemase producing Enterobacteriaceae. Emerg. Infec. Dis., 18: 1503-7.

Woodford, N., Tierno, P.M., Jr, Young, K., et al. 2004. Outbreak of Klebsiella pneumoniae producing a new carbapenem-hydrolyzing class A betalactamase, KPC-3, in a New York Medical Center. Antimicrob. Agents Chemother., 48(12): 4793-4799.

Yigit, H., Queenan, A.M., Anderson, G.J., Domenech-Sanchez, A., Biddle, J.W., Steward, D., et al. 2001. Novel carbapenem-hydrolyzing Betalactamase, KPC-1, from a carbapenemresistant strain of Klebsiella pneumoniae. Antimicrob. Agents Chemother., 45(4): 1151-61.

\section{How to cite this article:}

Rajeswari Jayakumar, Vijayalakshmi Arumugam and Meerah Srinivasagam. 2017. Carbapenems Resistance Klebsiella Species Isolated from Various Clinical Samples in a Tertiary Care Hospital. Int.J.Curr.Microbiol.App.Sci. 6(7): 2194-2199. doi: https://doi.org/10.20546/ijcmas.2017.607.318 